LETTERS

If you have a burning desire to respond to a paper published in Sex Transm Inf, why not make use of our "rapid response" option?

Log on to our website (www.sex transinf.com), find the paper that interests you, click on "full text" and send your response by email by clicking on "eletters submit a response".

Providing it isn' $\downarrow$ libellous or obscene, it will be posted within seven days. You can retrieve it by clicking on "read eletters" on our homepage.

The editors will decide, as before, whether to also publish it in a future paper issue.

\section{Resurgence of syphilis in England}

In their commentary on the resurgence of syphilis in England, Fenton et al cover issues surrounding controlling outbreaks of syphilis, quoting parallels in the United States, and identify the need for simple treatment, preferably with a single dose regimen. Two important differences between the two countries in management strategy that could be relevant to the current UK situation are, however, not discussed. Firstly, variation in penicillin treatment regimen: in the United States single dose benzathine penicillin is recommended for primary, secondary, and early latent syphilis, ${ }^{2}$ whereas in the United Kingdom, 10 days of procaine penicillin is the preferred regimen except when compliance is likely to be a problem. ${ }^{3}$ Secondly, epidemiological treatment of sexual contacts is a policy pursued actively in the United States but not in the United Kingdom. ${ }^{4}$

These differences have evolved as responses to the epidemiological patterns of syphilis in the two countries. In the United States outbreaks of syphilis are well recognised whereas in the United Kingdom they are a relatively new phenomenon. Given the success in managing outbreaks in the United States it might be relevant to review proved aspects of syphilis management using single dose benzathine penicillin, as in the United States, that could be applied in the United Kingdom. Adopting this treatment regimen would also open the way for other effective treatment strategies such as selective mass treatment and epidemiological therapy in high prevalence populations. The issue of compliance with protracted regimens of procaine penicillin, a problem that takes up considerable time of genitourinary medicine clinic staff, would also be solved. Although concerns about using a single dose of benzathine penicillin in HIV positive subjects with advanced immunosuppression have been raised, possible treatment failures are still at the case report stage. Furthermore, there are no documented treatment failures in Africa where the prevalence of syphilis and HIV is the highest. World Health Organization currently recommends that HIV infected patients with early syphilis are treated no differently from non-HIV infected patients and recommends single dose therapy.

In trying to identify new interventions to improve STI control for limiting the spread HIV, the basic principles of STI control are, if anything, more relevant today compared with the past. Although the issues and arguments raised here have been discussed in depth previously, ${ }^{6}$ they bear repeating in the light of the recent increase in syphilis in the United Kingdom.

N O'Farrell

Ealing Hospital, Pasteur Suite Infection and Immunity Unit, Genito-Urinary Medicine, Uxbridge Road, Southall, UK

\section{References}

1 Fenton KA, Nicoll A, Kinghorn G. Resurgence of syphilis in England: time for more radical and nationally coordinated approaches. Sex Transm Infect 2001;77:309-10.

2 CDC. 1998 Guidelines for treatment of sexually transmitted diseases. MMWR 1998;47:RR 1.

3 Clinical Effectiveness Group. National guideline for the management of early syphilis. UK national guidelines on sexually transmitted infections and closely related conditions. London: Association for Genitourinary Medicine, Medical Society for the Study of Venereal Diseases, 2001

4 Cates W, Rothenberg RR, Blount JH. Syphilis control. The historic context and epidemiologic basis for interrupting sexual transmission of treponema pallidum. Sex Transm Dis 1996;23:68-75.

5 World Health Organization. Guidelines for the management of sexually transmitted infections. Geneva: WHO, 2001.

6 Willcox RR. Epidemiological treatment in non-venereal and in treponemal diseases. $\mathrm{Br} J$ Vener Dis 1973;49:107-15.

Accepted for publication 7 March 2002

\section{Vulvovaginitis due to fluconazole resistant Candida albicans following self treatment with non-prescribed triazoles}

Resistance of Candida albicans to triazoles is uncommon with short term treatment but has been increasingly reported in immunocompromised patients, including those with HIV infection who are receiving long term systemic or maintenance therapy. Vaginal triazole resistant $C$ albicans isolates are extremely rare in non-immunocompromised HIV seronegative women. ${ }^{1}$ To our knowledge, only a single case has been reported to date. As over the counter oral triazole antifungals are now widely available there is potential for drug resistance to increase. We report another case of vulvovaginitis due to triazole resistant $C$ albicans in an otherwise healthy woman.

The patient was a 28 year old woman who presented with symptoms of vulval pruritis and profuse vaginal discharge for six months. She was not taking regular medication but had used clotrimazole and fluconazole several times in the preceding months with no clinical improvement. On examination, the vulva looked healthy but the vagina was erythematous and white plaques were noted. The cervix appeared normal and bimanual pelvic examination was unremarkable. The patient declined HIV serology but was fit and well with no stigmata of HIV infection and no risk factors.
Microscopic examination of vaginal secretions did not reveal any yeast blastospores or pseudohyphae, nor any clue cells or trichomonads. However, $C$ albicans was isolated on culture. In view of the documented history of a lack of response to topical and oral azoles, the patient was treated with nystatin pessaries daily for two weeks, while antifungal sensitivity tests were being performed. The patient returned to clinic two weeks later and reported only slight improvement in her symptoms despite using vaginal nystatin as prescribed. Unfortunately, the sensitivity test results were not available at this time and the patient subsequently failed to attend the clinic.

In vitro sensitivity testing by the Mycology Reference Laboratories (Bristol, UK) using the NCCLS M27A assay ${ }^{3}$ revealed that the vaginal $C$ albicans isolate was resistant to both fluconazole (minimum inhibitory concentration $(\mathrm{MIC})>64 \mu \mathrm{g} / \mathrm{ml}$ ) and itraconazole $($ MIC $>16 \mu \mathrm{g} / \mathrm{ml})$ but sensitive to nystatin $(\mathrm{MIC}=2 \mu \mathrm{g} / \mathrm{ml})$, miconazole $(\mathrm{MIC}<0.125 \mathrm{mg} / \mathrm{l})$ and clotrimazole $(\mathrm{MIC}=0.25 \mathrm{mg} / \mathrm{l})$.

In vitro susceptibility to antifungal agents appears to be a poor predictor of therapeutic success but in vitro resistance, defined by high MIC levels, correlates well with clinical resistance. ${ }^{45}$ However, despite the lack of a clear correlation between in vitro susceptibility and clinical response such data may assist the selection of alternative antifungal agents in cases of apparent clinical resistance.

As the patient did not attend for review, we do not know whether a microbiological cure was effected by this therapy, and therefore, we cannot exclude the possibility that the patient's symptoms were due to other pathology. Nevertheless, this case indicates that the possibility of triazole resistant $C$ albicans should be considered in non-immunocompromised individuals with refractory vulvovaginal symptoms and a history of self medication.

L Dorrell, A Edwards

Harrison Department, Radcliffe Infirmary, Oxford OX2 6HE

Correspondence to: $\operatorname{Dr}$ A Edwards; anne.edwards@orh.nhs.uk

\section{References}

1 Lynch ME, Sobel JD, Fidel PL Jr. Role of antifungal drug resistance in the pathogenesis of recurrent vulvovaginal candidiasis. J Med Vet Mycol 1996;34:337-9

2 Sobel JD, Vazquez JA. Symptomatic vulvovaginitis due to fluconazole-resistant Candida albicans in a female who was not infected with human immunodeficiency virus. J Infect Dis 1996;22:726-7.

3 National Committee for Clinical Laboratory Standards. Reference method for broth dilution antifungal susceptibility testing of yeasts. Proposed Standard M27-P. Villanove, PA: NCCLS, 1992.

4 Cameron ML, Schnell WA, Bruch S, et al. Correlation of in vitro fungal resistance of Candida isolates in relation to therapy and symptoms of individuals seropositive for human immunodeficiency virus type 1. Antimicrob Agents Chemother 1993;37:2449-53.

5 Rex JH, Pfaller MA, Barry AL, et al. Antifungal susceptibility testing of isolates from a randomised, multicentre trial of fluconazole versus amphoteracin $B$ as treatment of non-neutropaenic patients with candidaemia. NIALD Mycoses Study Group and the Candidaemia Study Group. Antimicrob Agents Chemother 1995;39:40-4. 
Table 1 Comparison of STI prevalences

\begin{tabular}{llll}
\hline & $\begin{array}{l}\text { Street sex workers } \\
(\mathrm{n}=102)\end{array}$ & $\begin{array}{l}\text { Brothel sex workers } \\
(\mathrm{n}=1664)\end{array}$ & p Value* \\
\hline $\begin{array}{l}\text { Chlamydia trachomatis } \\
95 \% \mathrm{Cl}\end{array}$ & $7(6.86 \%)$ & $44(2.64 \%)$ & 0.001 \\
Neisseria gonorrhoeae & 2.8 to 13.6 & 1.92 to 3.53 & 0.76 \\
$95 \% \mathrm{Cl}$ & $1(0.98 \%)$ & $12(0.72 \%)$ & \\
Trichomonas vaginalis & 0.031 to 5.34 & 0.37 to 1.25 & $<0.001$ \\
$95 \% \mathrm{Cl}$ & $7(6.86 \%)$ & $4(0.24 \%)$ & \\
\hline
\end{tabular}

*Prevalence for the difference in the proportion of street sex workers and brothel sex workers with each infection.

\section{Will the legalisation of street sex work improve health?}

The legalisation and regulation of street sex work in Victoria, Australia, is likely to improve the health of street sex workers and their clients.

In Victoria, street sex work is illegal. In comparison, brothel and escort agency sex work is legal, and these individuals are required by law to have monthly certification of STI screening. Any incident infections are detected early and treated so that the prevalence of STIs is low. ${ }^{1}$ There is no such requirement for street sex workers, who have infrequent STI screens and high rates of STIs.'

Following an acceptability and feasibility study, ${ }^{1}$ funding was secured for the Inner South Community Health Service Youth Health Bus to offer STI screening using self administered samples to street sex workers. Female workers provided a tampon sample and male and transsexual workers a first passed urine sample. These samples were then tested by polymerase chain reaction (PCR) for Chlamydia trachomatis, Neisseria gon orrhoeae, and Trichomonas vaginalis. ${ }^{2}$ The Youth Health Bus provides support and condoms to street sex workers several evenings a week in St Kilda, Melbourne's street sex worker precinct. They have been offering self collected samples for testing since mid-1999.

Over a 2 year period 102 samples were collected yielding 15 positive results $(14.7 \%$, $95 \%$ CI: $7.8 \%$ to $21.6 \%$ ). This group included 81 females, 20 males, and one transsexual individual, with a mean age of 24 years (range 16-43). C trachomatis was identified in seven sex workers, $T$ vaginalis in seven, and $N$ gonorrhoeae in one. These high prevalences of STIs are compared with the low prevalences in brothel sex workers attending Melbourne Sexual Health Centre in the corresponding time (table 1 above). These street sex workers were also not having regular STI screens, with only eight (7.9\%) of the 102 individuals reporting an STI screen in the preceding month, and $12(11.8 \%)$ who had never had one.

The legalisation of street sex work would allow it to be regulated and hence make regular STI screening a legal requirement. Recently, a 2 year trial of designated areas for street sex work in Melbourne has been recommended. ${ }^{3} \quad$ These recommendations would protect the health of street sex workers and their clients, in addition to the targeted intervention described here. Further research is needed into the best health promotion model for street sex workers.

\section{Contributors}

$\mathrm{AM}$ and $\mathrm{CF}$, design, analysis, and writing of paper; ST and SG, laboratory analysis and interpretation PL and PR, design and collection of specimens.

A N Morton

Melbourne Sexual Health Centre, 580 Swanston Street, Carlton, Victoria, 3053, Australia

S N Tabrizi

Molecular Microbiology Laboratory, Royal Women's Hospital, 132 Grattan Street, Carlton, Victoria, 3053, Australia

S M Garland

Royal Women's and Royal Children's Hospitals, 132 Grattan Street, Carlton, Victoria, 3053

Australia

$P \mathrm{~J}$ Lee

Inner South Community Health Service, 18 Mifford Street, St Kilda, Victoria, 3184, Australia
P E Reid

Inner South Community Health Service, 18 Mifford Street, St Kilda, Victoria, 3184, Australia

C K Fairley

University of Melbourne and Director of Melbourne Sexual Health Centre, 580 Swanston Street, Carlton, Victoria, 3053, Australia

Correspondence to: Anna Morton, Melbourne Sexual Health Centre, 580 Swanston Street, Carlton, Victoria, 3053, Australia; amorton@mshc.org.au

\section{References}

1 Morton AN, Wakefield T, Tabrizi SN, et al. An outreach programme for sexually transmitted infection screening in street sex workers using self-administered samples. Int $\mathrm{J}$ STD AIDS 1999; 10:741-3

2 Tabrizi SN, Paterson B, Fairley CK, et al. A self-administered technique for the detection of sexually transmitted diseases in remote communities. J Infect Dis 1997; 176:289-92.

3 Attorney-General's Street Prostitution Advisory Group Interim Report. September 2001.

Accepted for publication 5 April 2002

\section{Adult and paediatric contact immunotherapy with squaric acid dibutylester (SADBE) for recurrent, multiple, resistant, mucocutaneous anogenital warts}

Treatment of recurrent anogenital warts is often troublesome, because, among the various treatment modalities currently available, few are uniformly effective or virucidal. ${ }^{1}$ Currently, topical immunotherapy with squaric acid dibutylester (SADBE) represents an effective treatment in the management of multiple plantar and common warts (table 1 below). ${ }^{2-5}$ In the genital area the use of SADBE has some limitations, as it may be associated with a significant degree of irritation that produces considerable discomfort to the patient. Based on studies showing excellent results $(87 \%$ of patients with complete resolution) achieved by some authors in treating condylomata acuminata of the endocervix with applications of dinitrochlorobenzene (DNCB), a substance similar to SADBE, utilising remote anatomical site applications to the skin of the arm, ${ }^{6}$ and our personal observation of spontaneous regression for untreated warts during contact immunotherapy with SADBE for alopecia areata, $^{5}$ we decided to compare the results

Table 1 Treatment of anogenital warts with SADBE: patient data

\begin{tabular}{|c|c|c|c|c|c|c|c|c|}
\hline $\begin{array}{l}\text { Patient } \\
\text { No }\end{array}$ & Sex & $\begin{array}{l}\text { Age } \\
\text { (years) }\end{array}$ & $\begin{array}{l}\text { Time of } \\
\text { onset }\end{array}$ & $\begin{array}{l}\text { Previous } \\
\text { treatments }\end{array}$ & Site of warts & Clinical features & $\begin{array}{l}\text { Area of application } \\
\text { of SADBE }\end{array}$ & $\begin{array}{l}\text { Number of } \\
\text { applications }\end{array}$ \\
\hline 1 & $\mathrm{~F}$ & 6 & 12 years & Multiple DTC & Perianal area & 8 keratotic and flat-topped papules & dorsum of left hand & 32 \\
\hline 2 & $\mathrm{~F}$ & 15 & 2 years & Multiple DTC & Perianal area & 5 flat-topped papules & dorsum of left hand & 38 \\
\hline 3 & M & 20 & 10 months & Multiple DTC & Shaft & 10 dome-shaped papules & shaft & 36 \\
\hline 4 & M & 24 & 17 months & $\begin{array}{l}\text { Podophyllin resin } \\
\text { Multiple DTC }\end{array}$ & Shaft & 15 dome-shaped papules & shaft & 34 \\
\hline 5 & $\mathrm{~F}$ & 25 & 6 months & $\begin{array}{l}\text { Imiquimod } 5 \% \\
\text { cream }\end{array}$ & $\begin{array}{l}\text { Labia majora and } \\
\text { minora, up to the } \\
\text { vaginal introitus }\end{array}$ & 2 warty plaques & pubic area & 17 \\
\hline 6 & M & 28 & 3 years & $\begin{array}{l}\text { Podophyllin resin } \\
\text { Multiple DTC }\end{array}$ & Coronal sulcus & $\begin{array}{l}1 \text { warty plaque surrounding the } \\
\text { coronal sulcus }\end{array}$ & pubic area & 39 \\
\hline 7 & M & 28 & 18 months & $\begin{array}{l}\text { Podophyllin resin } \\
\text { Multiple DTC }\end{array}$ & Shaft & 12 dome-shaped papuls & shaft & - \\
\hline 8 & M & 29 & 9 months & $\begin{array}{l}\text { Podophyllin resin } \\
\text { Multiple DTC } \\
\text { Surgical excision }\end{array}$ & Coronal sulcus & $\begin{array}{l}1 \text { warty plaque surrounding the } \\
\text { coronal sulcus }\end{array}$ & pubic area & 37 \\
\hline 9 & M & 70 & 16 months & Multiple DTC & Shaft & 20 flat-topped, dome-shaped papules & shaft & 32 \\
\hline
\end{tabular}


obtained in the management of multiple and resistant anogenital warts by applying SADBE directly to the lesions with those obtained by applying it to remote unaffected areas.

From June to December 1999, nine patients, seven adults (mean age 32 years) and two children (mean age 10.5 years), were treated. Following sensitisation by topical application of 3\% SADBE in acetone directly to the skin of the pubic region in adults and to the back of the hands in children, serial dilutions $(0.0003 \%$ to $3 \%)$ were tested 2 weeks later on the same skin area in order to evaluate the minimal concentration capable of eliciting an eczematous reaction. Subsequently, the application of the compound was performed in the clinic by trained staff twice a week. SADBE application varied by age of patients and anatomical site of lesion. In children, SADBE was applied to the dorsal left hand; in adults it was directly applied to lesions located on skin, or to the pubic area when lesions were located on mucosae. If an eczematous reaction was not elicited after 1 week, an incrementally higher concentration was applied. If a strong reaction ensued, the treatment was discontinued for 3-6 days and an incrementally lower concentration was used at the following visit.

A total of eight patients completed the therapy, showing complete resolution after a mean of 16 weeks of treatment, with variable concentrations of SADBE ranging from $0.0003 \%$ to $0.3 \%$ (table 1). Local side effects (erythema, desquamation, cutaneous oedema, pruritus, burning, and pain) were generally mild and well tolerated. No relapses occurred during an 18 month follow up.

Clinical resolution and length of treatment in patients treated by applications to remote areas was comparable with those in which SADBE was applied directly to lesions. These results not only substantiate the efficacy and safety of topical SADBE in the treatment of multiple recurrent/recalcitrant anogenital warts, but also indicate a possible systemic effect of contact immunotherapy, suggesting that the mechanism of action of SADBE could be more than a non-specific inflammatory reaction or a local cell mediated process triggered by a non-wart antigenic immune stimulus.

F Dall' Oglio, M R Nasca, O D'Agata, G Micali

Dermatology Clinic, University of Catania, Italy

Correspondence to: Giuseppe Micali, MD, Clinica

Dermatologica, Università di Catania, Piazza S Agata La Vetere, 6, 95124 - Catania, Italy; cldermct@dimtel.nti.it

\section{References}

1 Sterling JC, Handfield-Jones S, Hudson PM. Guidelines for the management of cutaneous warts. Br J Dermatol 2001;144:4-1 1.

2 Licastro R, Micali G, Gasparri O, et al. Trattamento delle verruche volgari multiple con dibutilestere dell'acido squarico (SADBE). Dermatol Clin 1991;3:174-7

3 Lee AN, Mallory SB. Contact immunotherapy with squaric acid dibutylester for the treatment of recalcitrant warts. J Am Acad Dermatol 1999;41:595-9

4 Micali G, Nasca MR, Tedeschi A, et al. Use of squaric acid dibutylester (SADBE) for cutaneous warts in children. Pediatr Dermatol 2000; 17:315-8.

5 Micali G, Dall'Oglio F, Tedeschi A, et al. Treatment of cutaneous warts with squaric acid dibutylester: a decade of experience. Arch Dermatol 2000;136:557-8.
6 Salvo A, Rojas I, Figueroa L, et al. Immunotherapy with cutaneous dinitrochlorobenzene in papillomavirus infection of the cervix uteri. Rev Chil Obstet Ginecol 1991;56:460-3

Accepted for publication 19 April 2002

\section{Recreational drug use by GUM clinic attendees}

Recreational drug use (RDU) is widespread in the United Kingdom. ${ }^{1}$ Studies have suggested that RDU is associated with an increased risk of STI or blood borne virus (BBV) acquisition..$^{2-6}$

A search of Medline 1966-2000 found no studies looking at the prevalence of RDU in UK genitourinary medicine (GUM) clinics. Therefore this study aimed to estimate the prevalence of RDU by attendees of the Plymouth GUM clinic and to see if the diagnosis of an STI is more common in illicit drug users.

The local research ethics committee approved the study. New patients attending the clinic between August and November 2000 completed a questionnaire which listed a number of drugs and asked about frequency of consumption and injecting drug use. Respondents were asked for their clinic number so that test results could be compared to drug use.

The completion rate was $76 \%$ (259/339). The mean age of respondents was 26 years (range 15-54) and 58\% were women.

Lifetime illicit RDU was reported by $64 \%$ (166/259, confidence interval (CI) 5.8) with $28 \%(72 / 259$, CI 5.5$)$ reporting use within the past month. Of 16-24 year olds, 66\% (87/132, CI 8.1) reported lifetime use while $34 \%$ (45/132, CI 8.1) reported recent use. There was no significant difference in use between men and women (66\% v 62\%). Figure 1 shows the proportion of clinic attendees who reported taking each drug.

Two people, $0.77 \%(2 / 259$, CI 0 to 1.87$)$ of respondents, reported injecting drug use. Most people, $64 \%$ (165/259), supplied their clinic number, and 32\% (52/165) were diagnosed with an STI. Men were more likely to be diagnosed as having an STI (OR 2.72, CI 1.40 to 5.28). The diagnosis of an STI was independent of units of alcohol drunk in the preceding month (OR 1.07, CI 0.78 to 1.46 ), and the use of illicit drugs whether in lifetime (OR 0.82, CI 0.43 to 1.60 ) or in the past month (OR 1.51, CI 0.71 to 3.20). Subjects who gave their number were less likely to take illicit drugs (OR 0.44, CI 0.25 to 0.77 ).

This survey has revealed a high prevalence of recreational drug use by attendees at a

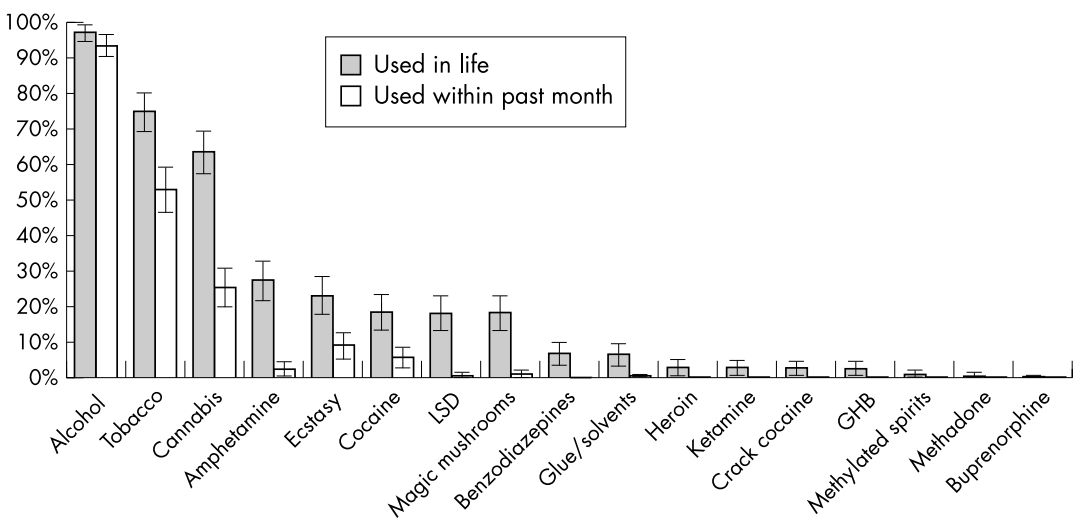

Figure 1 Proportion of respondents reporting use of each drug. Error bars show 95\% confidence interval.
GUM clinic. Comparing the data with the 2000 British Crime Survey (BCS) shows that the proportion of clinic 16-24 year olds who admitted to illicit drug use within the past month is greater than the same age group surveyed in the BCS (OR 2.32 CI 1.59 to 3.37). Likewise, lifetime use was more common (OR 1.86 , CI 1.29 to 2.69 ).

There is a low prevalence of injecting drug use; this might be due to under-reporting. An alternative explanation is that this high risk group is not accessing the clinic. If this is the case it would support moves to set up an outreach clinic.

This study found that the diagnosis of an STI is independent of RDU. This might be because RDU is so common that it is no longer a useful discriminator; alternatively, a larger sample size might have found evidence of an association.

In conclusion, although RDU is common, injecting drug use appears to be rare in this group. The findings of this survey have implications for service provision.

\section{Acknowledgement}

I thank Steven Skov for his criticism of the manuscript.

Conflict of interest: none.

S D K Baguley

Department of Genitourinary Medicine, Derriford Hospital, Plymouth, UK

Correspondence to: Genitourinary Medicine Department, Bristol Royal Infirmary, Bristol, UK; stevebaguley@bigfoot.com

\section{References}

1 Ramsay M, Baker P, Goulden C, et al. Drug misuse declared in 2000: results from the British Crime Survey. Home Office Research Study 224. London: Home Office, 2001.

2 Swanson JM, Remy L, Chenitz WC, et al. Illicit drug use among young adults with genital herpes. Public Health Nurs 1993;10:135-40.

3 Anonymous. Syphilis in Bristol 1997-8: an update. Commun Dis Rep CDR Wkly 1998:8:413,416.

4 Biglan A, Metzler CW, Wirt R, et al. Social and behavioral factors associated with high-risk sexual behaviour among adolescents. J Behav Med 1990;13:245-61.

5 Chiasson MA, Stoneburner RL, Hildebrandt DS, et al. Heterosexual transmission of HIV-1 associated with the use of smokable freebase cocaine (crack). AIDS 1991;5:1121-6.

6 Zenilman JM, Hook EW, Shepherd M, et al. Alcohol and other substance use in STD clinic patients: relationships with STDs and prevalent HIV infection. Sex Transm Dis 1994;12:220-4.

Accepted for publication 23 April 2002 


\section{HIV negative certification and sexual health issues facing performers in the adult entertainment industry in the UK}

The production of adult entertainment videos in the United Kingdom has increased in the past 2 years. In July 2000 the British Board of Film Classification introduced changes to the "Restricted 18" ("R18") classification of videos, legalising the sale of videos featuring explicit images of real sex to people over the age of 18 in registered sex shops licensed by local councils. Changes to the "R18" classification were introduced in response to the incorporation of the Human Rights Act into the British legal system, making freedom of expression part of British law. There are currently around 90 licensed sex shops in Britain, and in the first half of this year the British Board of Film Classification has already classified 485 "Rl8" videos, compared to a total of 651 videos in 2001 .

The majority of adult entertainment videos are produced showing images of real unprotected sex without condoms, ${ }^{2}$ and concerns that these videos may give some viewers an impression that sex without condoms is safe has prompted a recent initiative by the British Board of Film Classification to introduce safer sex health messages as a standard on all "Rl8" vid eos. This initiative is supported by the Department of Health, the Public Laboratory Service, and the Terrence Higgins Trust. The British Board of Film Classification has indicated a willingness to collaborate with the major distributors of "Rl8" videos in Britain in the production of a safer sex message. It is notable that such safer sex messages already exist in some adult videos produced in the United States.

Central to the health and safety issues for performers of adult entertainment videos is the regulation of HIV negative certification. In the United States, where the estimated yearly income from pornography in 1997 was $\$ 2.5$ billion, ${ }^{3}$ the adult entertainment industry responded to the HIV outbreak in the 1980 s by introducing regular compulsory HIV antibody testing of performers involved in the production of images showing real unpro tected sex. In 1998 former performers set up a clinical service, AIM Health Care Foundation, in collaboration with medical experts providing sexual health care and information specifically aimed at performers in the adult entertainment industry. AIM Health Care Foundation provides HIV testing and certification, STI testing and treatment, and provides free condoms, lubrication, and offers information and counselling. AIM Health Care Foundation serves 400 clients per month and runs an effective monitoring and partner notification system using a PCR/DNA test showing negative HIV status within the past 28 days. AIM Health Care Foundation also holds a HIV database that allows producers to confirm that the performers comply with this testing programme, which has succeeded in controlling the spread of HIV in the adult entertainment industry. AIM Health Care Foundation recommends regular STI screenings to all their clients. It estimates that in Los Angeles, where the majority of the adult entertainment industry in the United States is based, the prevalence of Chlamydia trachomatis genital infection is $10 \%$ higher than the national average. ${ }^{4}$ By providing health care and information, AIM Health Care Foundation has contributed towards the development of a more coherent and accountable infrastructure in the adult entertainment industry in the United States.
Although the recent legal changes to the "R18" category have contributed to the growth of the adult entertainment industry in the United Kingdom, the industry still lacks a coherent infrastructure. Production budgets are low and there are no working contracts for performers. The result is that earnings and average employment periods for performers in the United Kingdom are lower compared with the United States. The lack of infrastructure in the adult entertainment industry in the United Kingdom is reflected in the poorly developed health and safety measures for performers. Previous research by one of us has found that, in contrast with the United States, where the industry standard requires performers to have a new HIV test every 30 days and to present their certificate on every job they are hired to do, the majority of performers in the United Kingdom have an HIV test no more than every 3 months, and very few performers have regular STI screenings. ${ }^{5}$ This work has also highlighted the discrepancies between the NHS sexual health clinics in their practices of issuing HIV certificates, and show that most performers in the United Kingdom prefer to use private clinics for this service. This also raises the governance issue of the need to ensure accuracy of identification in issuing these certificates in order to avoid any fraudulent HIV negative certificates.

We have now developed a collaborative project, based on the original research by LG into the health issues in the adult entertainment industry. The HIV/GUM Directorate of the Chelsea and Westminster Hospital are conducting a pilot survey of the detailed sexual health of adult performers in order to define their risk of sexually transmitted infections in work and private lives, as well as assessing their awareness of sexual health issues. Clearly the availability of condoms and HIV negative certification is an important issue for the strategic planning of sexual health services which data from our survey should inform.

\section{Contributors}

LG conducted the original research and wrote this letter and SEB is primary investigator.

L Gabrielsen Independent consultant researcher

S E Barton

HIV/GUM Chelsea and Westminster Healthcare NHS Trust Correspondence to: Dr Barton hilary.gough@chelwest.nhs.uk

\section{References}

1 British Board of Film Classification www.bbfc.co.uk/website/statistics.nsf. 20 June 2002.

2 AIM Health Care Foundation: as a main distributor of free condoms to the adult entertainment industry, AIM Health Care Foundation estimates that $18 \%$ of the heterosexual adult films produced in the USA feature performers wearing condoms. Research conducted by LG suggests that this figure is lower in British and in Europe July 2001. AlM Health Care Foundation, estimate that $18 \%$ of heterosexual adult films in the USA are today produced with the use of condoms. http://aim-med.org. July 2001.

Research conducted by LC suggests that this figure is lower in the UK and in Europe. Gabrielsen Lisa. Risk of consent. MA Dissertation, University of London, 2001

3 Skee M, 1997 as cited by J A Thomas In: Weitzer R, ed. Sex for sale. Prostitution, pornography, and the sex industry. London: Routledge, 2000:49.

\section{AIM Health Care Foundation:} http://aim-med.org. July 2001.

Accepted for publication 7 May 2002

5 Gabrielsen L. Risk of consent. MA Dissertation. London: University of London 2001.

\section{BOOK REVIEWS}

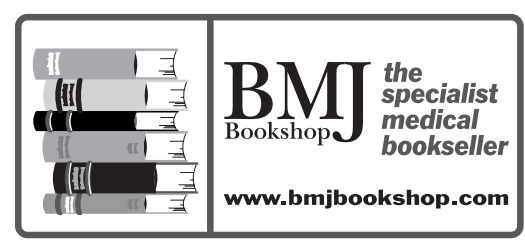

ABC of AIDS. 5th ed.

Ed M W Adler. Pp 128; £17.95. London: BM Books, 2001. ISBN 0727915037.

Writing a good textbook on HIV infection is very difficult. Large textbooks that attempt to be comprehensive face the problem that, in what is now such a vast and still rapidly moving field, they are out of date by the time they are published. Smaller textbooks on the other hand have to decide what to leave out. This book is clearly aimed as an introduction to the subject for people without much experience of HIV. Although not attempting in any way to be comprehensive, it is often remarkably detailed despite its brevity. I think that it is much the best of the available short textbooks for a general readership. It is (relatively) cheap and unlike other books, as it is so concise is likely to be read by those who buy it.

The best chapter is also the longest, on "Treatment of infections and antiviral therapy" (what else is there left?), which forms the core of the book. There are also two very readable chapters written by patients. If read together these three chapters make clear the profound changes that combination antiretroviral therapy has produced since 1996, in a way that some other chapters curiously do not. The chapter on gastrointestinal manifestations, for example, has not been revised significantly in this edition to reflect the impact of HAART.

The book has some shortcomings. There is little mention of the issue of late presentation of disease, which is a particular problem in the United Kingdom especially among those with heterosexually acquired infection; the sections on counselling and epidemiology fail to reflect this. The massive problem of co-infection with hepatitis $\mathrm{C}$ is touched on only briefly in two chapters. There is no separate section on women with HIV infection (although mother to child transmission is well covered in the paediatric section). While the colour illustrations are generally excellent, the reproductions of chest $x$ rays are not so good, and the same mangled slide of a patient with pulmonary lymphoma found in earlier editions of the book is reproduced unchanged in this one. Finally, post-exposure prophylaxis is poorly dealt with, which is a shame as this is a topic likely to be of major interest to the general reader who has just pricked his or her finger with a bloodstained needle.

However, despite these qualifications, this really is a very good book. I hope the sixth edition is even better.

Duncan Churchill Consultant physician, Lawson Unit Royal Sussex County Hospital, 'Eastern Road,
Brighton BN2 5BE, UK 


\section{Human papillomaviruses. Clinical and Scientific Advances.}

Ed JC Sterling, SK Tyring. Pp 153; $£ 65.00$. London: Arnold Publishers, 2001. ISBN 0-340-742 15-1.

Most of us have had an encounter with warts at some time in our lives. We try to freeze, poison, or corrode them, occasionally resorting to surgery, laser vaporisation and, latterly, immunotherapy. Our modest success at treatment only underscores the general public's perception that warts are a common but incurable nuisance. All this trouble from a family of viruses with a host range that spans the animal kingdom and an astonishing spectrum of disease manifestations. The development and subsequent exploitation of increasingly sophisticated molecular techniques over the past 30 years have led to a rapid increase in the understanding of the biology of papillomaviruses, especially human papillomaviruses (HPVs). Much of this effort has focused on the propensity of certain HPV types to contribute to malignant transformation and, increasingly, on the potential for developing more effective therapies, including vaccines to prevent HPV associated cancers.

Jane Sterling and Stephen Tyring have managed to assemble a panel of clinical and scientific experts working on HPV and have produced a highly readable and concise account of the recent advances in our understanding of this fascinating infection. The chapters are laid out logically in three main parts-Molecular and Cellular Aspects, Diseases and Infections, and Future Prospects: treatment and basic research. The book is beautifully illustrated throughout, providing greater clarity in explaining complex molecular mechanisms as well as good clinical examples of the different types of HPV related diseases. Some overlap in coverage is inevitable in a multiauthor textbook but this does not detract from the consistently high quality of the finished product.

This book is ideal for both junior and senior staff who need to acquire some knowledge of the mechanisms and spectrum of HPV disease. The scientific reviews should prove useful to those sitting for postgraduate examinations and other (mischievous) purposes. Those of you who may have grown rather neurodystrophic from the HIV arrivistes' staff room chants of Intention to Treat, BLQ (I was always under the impression they were talking about bacon, lettuce, and tomato sandwiches), CYP3A4 inhibition, and $\mathrm{K} 103 \mathrm{~N}$ at every available opportunity will welcome this slim, lean textbook. A sharp riposte on the lines of, "that's all very well, but did you know that the HPV 16 and $18 \mathrm{E7}$, like E1A and SV40 large T bind to the family of cellular proteins which include pRb, p107, and p130 and that the latter two complex with regulators of the cell cycle including members of the E2F family, cyclin $\mathrm{A}$, and cyclin $\mathrm{E}$, and participate in the regulation of both G1 and G2 cell cycle blocks ...?" [p 26] should be sufficient to keep their overblown egos in check, albeit temporarily.

Richard Lau

St George's Hospital, London, UK

\section{Understanding thrush, cystitis and women's genital symptoms.}

By Caroline Bradbeer. Pp 96; £3.50. London: Family Doctor Publications in association with the BMA, 2001. ISBN 1-903474-00-0.

This book certainly compares favourably with some of the offerings available in our local pharmacies and health food shops. Overall, it gives a concise summary of female genital infective problems and physiology in clear and accessible language. This is supplemented by a series of clear illustrations, case discussions, and summary boxes. As well as the general public, medical students and nurses might find this a useful and informative book.

While there were no major reservations about the book the title did seem a little misleading. Although "thrush" is covered well and sensibly it is only a relatively minor part of this book. Maybe it should have been called "women's genital symptoms-including thrush, cystitis, and other infections." Also it is not really relevant to perimenopausal and postmenopausal women and this isn't made clear in the introduction. The only real shortcoming was that painful sex was given too little space and although vulvodynia is mentioned and indexed there is no mention of the vulval vestibulitis syndrome despite this being commonly misdiagnosed as "problem thrush."

A good little book for the pharmacy bookshelf and to recommend to patients.

David J White, An Vanthuyne Hawthorn House, Heartlands Hospital, Birmingham B9 5SS

\section{NOTICES}

International Herpes Alliance and International Herpes Management Forum

The International Herpes Alliance has introduced a website (wwwherpesalliance org) from which can be downloaded patient information leaflets. Its sister organisation the nternational Herpes Management Forum (website: www.IHMF.org) has launched new guidelines on the management of herpesviru infections in pregnancy at the 9th International Congress on Infectious Disease (ICID) in Buenos Aires.

\section{Pan-American Health Organization, regional office of the World Health Organization}

A catalogue of publications is available online (www.paho.org). The monthly journal of PAHO, the Pan American Journal of Public Health, is also available (subscriptions: pubsvc@tsp.sheridan.com).

\section{8th Congress on Sexually Transmitted Infections IUSTI-Europe 2002}

12-14 September 2002, Vienna, Hofburg Congress Center.

Chair of the Congress, Director of the European Branch of IUSTI: Angelika Stary, MD (Austria)

Further details: Angelika Stary, c/o Administrative and Scientific Secretariat, Vienn Academy of Postgraduate Medical Education and Research, Alser Strasse 4, A-1090 Vienna, Austria (tel: (+43 1) 4051383 13; fax: (+43 l) 40782 74; email: iusti 2002@medacad.org; website: www.iusti-europe-2002.org).

26th National Conference of the Indian Association for the Study of Sexually Transmitted Diseases \& AIDS

18-20 October 2002, All India Institute of Medical Sciences, New Delhi, India

The last date for submission of abstracts for free papers is 1 September 2002. The registration fees for foreign delegates is $\$ 50$ (SAARC countries) and \$100 (other countries).

Further details: Indian Association for the Study of Sexually Transmitted Diseases \& AIDS (fax: (0)91 011686 2663; email: iasstd2002@sify.com). 